\title{
O Nordeste brasileiro das aberturas de telenovelas da TV Globo (1989-1999)
}

\author{
The brazilian northeast in the opening titles of TV Globo's soap operas (1989-1999)
}

Jaíne Cintra, Paulo Carneiro da Cunha Filho

Aberturas, telenovela, Nordeste brasileiro, motion graphic design

Este artigo analisa as soluções de design que articularam conceitos e ideias sobre o Nordeste nas aberturas de telenovelas exibidas pela TV Globo entre 1989 e 1999. Os estereótipos presentes fazem parte das estratégias discursivas do discurso midiático sobre a região, porém, o design aliado à tecnologia, adicionou uma nova camada de estranheza a estes valores: a anamorfose. Partimos das considerações do livro A invenção do Nordeste e outras artes, (Albuquerque Júnior, 2011), para o contexto histórico e discutimos os resultados gerados pela Análise Cultural de Conteúdo em três trabalhos: Tieta (1989), Pedra sobre Pedra (1992) e A Indomada (1997). Sendo Tieta e A Indomada reprisadas também em 2020. O período analisado está inserido no momento em que houve a abertura democrática no Brasil, em 1989, até um pouco antes da disseminação da internet, nos anos 2000. A fim de traçarmos um padrão de representação ao breve contexto das obras, adicionamos a avaliação da técnica, histograma e personagens centrais.

Opening title, soap operas, brazilian northeast, motion graphic design

This article discusses design solutions to articulate concepts and ideas about the brazilian northeast in openings of soap operas aired by TV Globo between 1989 and 1999. The stereotypes present are part of the discursive strategies of the media discourse about the region, however, the design allied to technology, added a new layer of strangeness to these values: the anamorphosis. We start from the considerations of the book A invenção do Nordeste e outras artes (Albuquerque Júnior, 2011), for the historical context and discuss the results generated by Cultural Content Analysis in three works: Tieta (1989), Pedra sobre Pedra (1992) and A Indomada (1997). Tieta and A Indomada were also rebroadcast in 2020. The period analyzed is from the time of the democratic opening in Brazil, 1989, until just before the spread of the internet in the 2000s. In order to trace a pattern of representation to the brief context of the works we add the evaluation of the technique, histogram and central characters.

\section{Introdução}

Um suposto Nordeste escapou pelas frestas das aberturas de telenovelas exibidas entre 1989 e 1999 pela emissora Globo. Avaliar o período após a abertura democrática até a popularização da internet, de certa forma, é observar reprises visuais de efeitos e de narrativas em um momento em que a TV era soberana. Nosso intuito é mostrar que as imagens têm seu próprio discurso e que o designer pode "escrever" com ineditismo ou por repetição do que é estabelecido.

Anais do $10^{\circ} \mathrm{CIDI}$ e $10^{\circ} \mathrm{CONGIC}$

Kelli C.A.S. Smythe, Rafael de Castro Andrade (orgs.)

Sociedade Brasileira de Design da Informação - SBDI

Curitiba | Brasil | 2021
Proceedings of the $10^{\text {th }} \mathrm{CIDI}$ and $10^{\text {th }}$ CONGIC

Kelli C.A.S. Smythe, Rafael de Castro Andrade (orgs.)

Sociedade Brasileira de Design da Informação - SBDI Curitiba | Brazil | 2021 
Vilém Flusser falou da linha cartesiana ocidental segundo a qual pensar significa seguir apenas a linha da escrita, e isso, de certa maneira, impede de dar o devido crédito às imagens como uma maneira de pensar (Flusser, 2017, p.111). As produzidas pela mídia são classificadas por ele como ficção-em-superfície, capazes de nos influenciar numa "mediação subjetiva, imagética" entre a mensagem e o telespectador. Já o texto científico, Flusser chama de ficção linear, funcionando como uma ponte entre a mensagem e o leitor de maneira mais clara, objetiva. Olhamos as imagens como essa ficção-em-superfície para desenvolver uma ficção linear, um pensamento em linha. Todos os frames foram investigados, ponto a ponto, como as linhas de um texto, com a ajuda de métodos da Análise Cultural de Conteúdo, que permite a conexão dos resultados matemáticos dos softwares com outros agrupamentos simbólicos.

Em um emaranhado histórico, o Nordeste apresentado pela equipe de design da TV Globo está amparado no que foi criado na literatura, na fotografia, no cinema, na pintura e na política, em um fenômeno que o historiador Durval Muniz de Albuquerque Jr. classifica como uma "criação imagético-ficcional da região". Olhamos para uma produção nacional exportada para diversos países, a telenovela, porque interessa-nos o rastro que o design, num dos produtos pioneiros da TV brasileira, deixa para afirmar ser o que não somos.

\section{Um Nordeste (in)evitável}

Em um momento que tanto se fala sobre o papel político do design (Pater, 2020; Lupton, 2020; Beccari, 2015), pode parecer clichê considerar produções de décadas passadas para apontar soluções estereotipadas. No nosso caso, as obras selecionadas são moldes ou matrizes até hoje vistas nas aberturas das telenovelas. De uma maneira ou de outra, o que foi iniciado naquela década permanece. São soluções de design e tecnologia que, por muitos anos, estão "adequadas" para representar o Nordeste.

No design gráfico, e sobretudo no motion graphic design, agrupamentos de estilos ou de soluções são feitos constantemente em catálogos ou sites especializados. São fontes de pesquisa e, inevitavelmente, indicam caminhos a replicar. É comum o agrupamento com caráter educacional feito sobre estúdios ou designers que atuam em mídias de vídeo, como nos sites stashmedia.tv, theinspirationgrid.com e artofthetitle.com. Não foi diferente com as soluções dadas pela TV Globo, que usou tecnologias e linguagens importadas das grandes produções do cinema. Atualmente, a emissora é umas das principais apoiadoras, ao lado da empresa Intel, do único congresso brasileiro de design e efeitos especiais: o VFX Rio, durante o qual são exibidas as produções desenvolvidas pela equipe de design e cadastrados profissionais para o banco de talentos.

O livro a Invenção do Nordeste e outras artes (Albuquerque Júnior, 2011) mostra como esse circuito de representações vindo da literatura, do cinema, da imprensa e dos interesses políticos contribuiu para que o reflexo da região no espelho fosse tão bem definido. Essa linguagem estranha, que escapa da compreensão, foi base para diversas produções. A união entre a vida cotidiana e enredos bíblicos ou do homem em simbiose com a natureza, tão 
presente na literatura de cordel, influencia roteiros e soluções visuais até hoje vistas, como no caso da telenovela Cordel Encantado (2011).

A literatura e as artes gráficas criaram subsídios para que o design executasse as experimentações tecnológicas mais avançadas na TV, quando assim foi possível. O discurso sociológico, naquilo que o sociólogo Gilberto Freyre (1900-1987) fixou em suas críticas de arte como deveria ser uma pintura regionalista: de paisagens de tons ocre ou de exuberância tropical (Albuquerque Júnior, 2011, p.166), também alimentou esse referencial, fornecendo um banco de imagens e enredos sobre a região. Por exemplo, na supersérie Onde nascem os fortes (2018), Figura1, uma abertura empoeirada, violenta e com sombras demarcadas representa uma fórmula que teve princípios norteadores bem firmados historicamente.

A seca surge na literatura como aquele fenômeno detonador de transformações radicais na vida das pessoas, desorganizando as famílias social e moralmente. A seca é responsabilizada, inclusive, pelos conflitos sociais na região, pela existência do cangaceiro e do beato, naturalizando-se as questões sociais. Se o sertão pega fogo, é graças ao sol inclemente. (Albuquerque Júnior, 2011, P.139)

Figura 1: Frames da abertura Onde nascem os fortes (2018). Fonte: Memória Globo
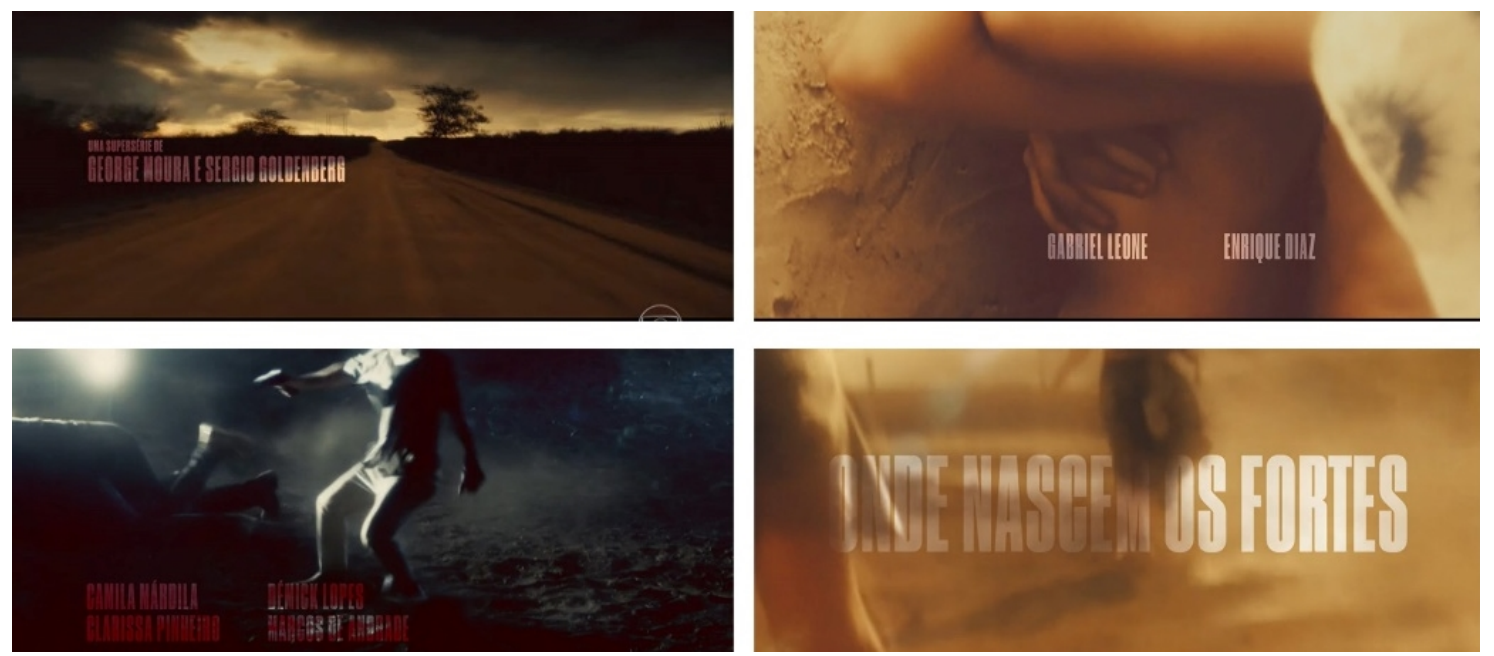

Outros movimentos contribuíram para essa linguagem visual persistente. Em 2020, comemorou-se os cinquenta anos do Movimento Armorial. Suas matrizes, cinco décadas depois, ainda são usadas para citar "uma arte erudita brasileira a partir de elementos da cultura popular" (Jucá; Oliveira; 2020). Como se o movimento, que teve por líder Ariano Suassuna (1927-2014), tivesse ensinado ao Brasil a olhar para si mesmo. Reforçando um suposto universo místico, medieval e brutal da região, passeou por diversas linguagens como as artes plásticas, a música, o teatro e a dança. Revelando uma região que transita entre o Diabo e Deus, explorada visualmente por diversos artistas, alimentando a possibilidade criativa que caminha pela estranheza. Nas obras de Gilvan Samico (1928-2013), a utilização da xilogravura e o uso do romanceiro popular apresentam os seres fantásticos, híbridos, vindos das lendas populares: "A estreita relação estabelecida por Samico com a cultura popular e a maneira de abordar o assunto veio a estabelecer boa parte dos fundamentos do que Suassuna definiu como uma Arte Armorial" (Fonseca, 2011, p.30). 
No quadro A luta dos homens (Samico, 1977), Figura 2, temos um enfrentamento entre dois homens, possivelmente instigados por uma criatura meio bode, meio humana, numa tensão criada entre o mundo celestial, o mundo terrestre e o mundo subterrâneo. No Nordeste, a criatura subterrânea com pés de bode é associada ao demônio (Fonseca, 2011, p.65). O enredo Armorial "tem sua história ainda governada pelos insondáveis desígnios de Deus. É um espaço que oscila entre Deus e o Diabo. É um jogo de cartas cujas regras não foram reveladas a ninguém." (Albuquerque Júnior, 2011, p.189). Essas narrativas que trabalham com o inexplicável foram interpretadas pelo departamento de arte e tecnologia da emissora, quando foi possível materializá-las visualmente, com softwares e equipamentos desenvolvidos inicialmente para o cinema americano.

Figura 2: A luta dos homens, 1977 de Gilvan Samico. Fonte: Fábio Fonseca



Essa vida criada pelas diversas artes, não só do movimento Armorial, sintetiza uma suposta aparência da região. O que ocorreu com a produção visual do artista argentino Carybé (1911-1997) sobre a cultura baiana, como o exemplo da Figura 3, ajuda a cristalizar um discurso homogeneizador.

É crucial apontar que todas as cenas de festas, terreiros, pescarias, igrejas, e ruas das cidades são fruto deste olhar, entrecortado pelo homem religioso, mas também de homem branco, estrangeiro e artista criativo .Todos os trabalhos se concentram nesta tentativa de representação de um mundo, o vivido e escolhido por Carybé. O que aparece em suas obras é uma escolha deste artista, a qual passou a configurar um imaginário popular, de signos e símbolos, do que se convencionou chamar de cultura baiana. (Maciel, 2015, p.192) 
Figura 3: Mulata Grande, Carybé, 1980. Fonte: Artes e artistas

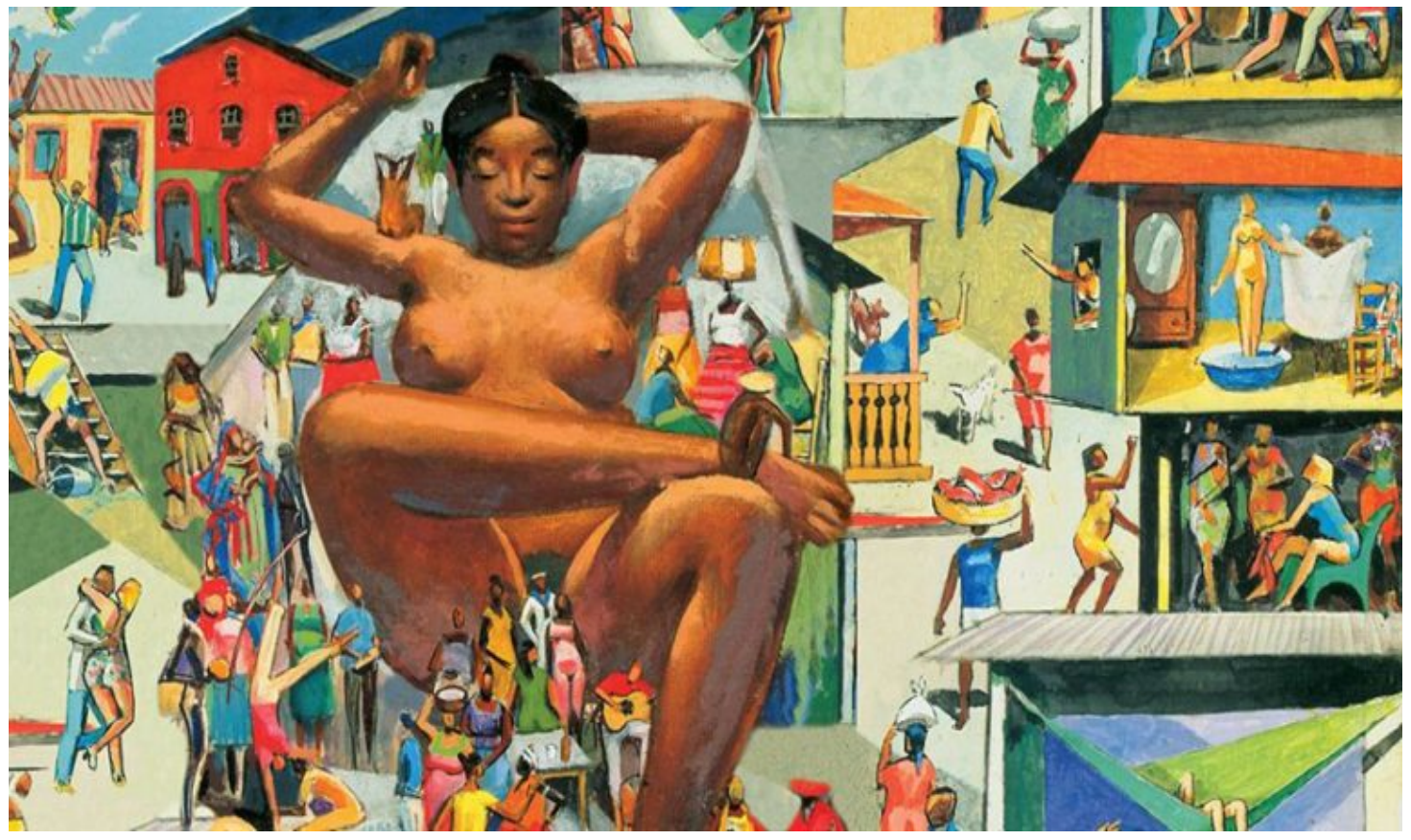

A visualidade, ancorada na literatura e, mais tarde, no cinema conformaram essa imagem nordestina. O mal assombro que convive com figuras do dia a dia. (Albuquerque Júnior, 2011, p.171). Esse realismo fantástico ou realismo maravilhoso foi bastante explorado na produção de telenovelas dos anos 1990. (Memória Globo, $A$ Indomada,s/p) .

A expressão realismo maravilhoso começou a ser utilizada dentro do contexto da literatura da América Hispânica a partir do prefácio do livro O reino deste mundo (1966), de Alejo Carpentier. Para Carpentier, o real maravilhoso hispano-americano ao contrário do surrealismo europeu, não estaria separado da realidade, mas sim, representaria uma maneira ampliada de percebê-la. O real maravilhoso estaria distante do "era uma vez" das fábulas, que afasta o texto da realidade do leitor, colocando-o em outro espaço, promovendo um pacto ficcional de que aquilo possivelmente não teria acontecido. O escritor aponta lo real maravilloso como uma percepção própria de uma realidade geográfica. (Carpeggiani, 2007, p. 18).

Uma percepção própria do espaço e dos costumes criou um Nordeste que é percebido não só pelos sudestinos e sulistas, mas pelos próprios nordestinos, numa geografia de sol castigante, da terra seca ou das praias, com seus corpos desnutridos pela fome, nus ou seminus como as personagens que habitam o litoral. As produções de aberturas de telenovelas buscam nesse acervo histórico as ferramentas necessárias para implementar técnicas e linguagens.

Os trabalhos iniciados no Globograph, departamento de arte e tecnologia da emissora do período estudado, fizeram o que não era possível "ilustrar" tecnicamente em vídeo acontecer. Tecnologias inéditas permitiram a transformação anamórfica de um ser em outro, impregnando ainda mais, na memória visual do país, um certo misticismo na relação do nordestino com o que é inexplicável ao expor corpos femininos nus ou seminus integrados a elementos da natureza. Na abertura de Tieta, 1989, é iniciada essa fórmula que permanece por anos, como pode ser visto em $A$ Indomada, 1997. Com muito recurso e inovação, uma nova linguagem na 
TV apresentou corpos que fogem da compreensão racional e que, de certa maneira, opõem-se ao estilo de vida cosmopolita. O discurso visual do motion graphic design materializou nestes trabalhos, durante todos os dias de exibição, uma narrativa que faz com que o Nordeste permaneça fora do tempo e da realidade.

A figura do designer como solucionador de problemas insiste em permanecer em diversas áreas de atuação. Essa definição ultrapassada deixa de considerar que as soluções são carregadas de ideias e princípios. Por muito tempo, Hans Donner representou um mito sobre o que seria e o que poderia fazer um designer na TV brasileira, concebendo trabalhos que forjavam articulações simbólicas e que ganhavam o status da "magia computacional" (Hans, 1988). A narrativa nordestina pareceu perfeita para executar efeitos e distorções, num momento em que o avanço da tecnologia permitiu e a censura do período militar no país havia chegado ao fim.

\section{Metodologia}

Nossa escolha temporal de análise vem do momento em que o departamento de arte da emissora consolida o início do uso de técnicas apuradas de efeitos visuais. Entre 1980 e 2000, o país testemunhou uma nova linguagem para as aberturas, sendo a década de 1990 marcada pelos experimentalismos e altos investimentos em computação gráfica.

Foram duas fases: a primeira, de caráter exploratório; a segunda, de caráter analítico. A nossa busca sempre foi baseada na relação da abertura e da representação de culturas, especificamente a do Nordeste. A partir da leitura do livro A invenção do Nordeste e outras artes (Albuquerque Júnior, 2011), procuramos processos para comprovar a repetição dos padrões estéticos e técnicos usados nas ilustrações das narrativas que se passam na região. Inicialmente, buscamos revisar a literatura e atualizar a pesquisa com a qual nos apoiamos para identificar métodos, processos e aspectos técnicos do departamento de arte utilizando como base a pesquisa $O$ design na teledramaturgia: um olhar sobre as vinhetas de aberturas das telenovelas da TV Globo (Dorneles, 2007).

O resultado foi uma amostragem não probabilística, porque não fizemos uma escolha aleatória entre as aberturas do período. Como nosso objetivo é buscar padrões não só de métodos de trabalho e soluções de design, mas também estéticos, resolvemos acrescentar ao levantamento processos vindos da Análise Cultural de Conteúdo, elaborada por Lev Manovich. Catalogamos todas as telenovelas do período e chegamos a 58 produções. No site Memória Globo, lemos a sinopse e assistimos aos resumos de capítulos para nos certificarmos sobre qual região elas estavam inseridas. Das 58 , sete telenovelas ambientadas no Nordeste foram encontradas, conforme a Tabela 1. 
Tabela 1: Produções entre 1989 e 1999

\begin{tabular}{lll}
\hline Ano e título & Período e horário de exibição & $\begin{array}{l}\text { Número de } \\
\text { capítulos }\end{array}$ \\
\hline 1989 - Tieta & $14 / 08 / 1989$ - 31/03/1990. Horário: $20 \mathrm{~h}$ & 196 \\
1992 - Pedra sobre Pedra & $06 / 01 / 1992-01 / 08 / 1993$. Horário: $20 \mathrm{~h} 30$ & 178 \\
1993 - Renascer & $08 / 03 / 1993-14 / 11 / 1993$. Horário: $20 \mathrm{~h} 30$ & 213 \\
1994 - Tropicaliente & $16 / 05 / 1994-30 / 12 / 1994$ Horário: $18 \mathrm{~h}$ & 194 \\
1996 - O Fim do Mundo & $06 / 05 / 1996$ - 14/06/1996 Horário: $20 \mathrm{~h} 40$ & 35 \\
1997 - A Indomada & $17 / 02 / 1997$ - 10/10/1997 Horário: $20 \mathrm{~h}$ & 203 \\
1998 - Meu Bem Querer & $24 / 08 / 1998$ - 19/03/1999 Horário: $19 \mathrm{~h}$ & 179 \\
\hline
\end{tabular}

Ao procurarmos no acervo Memória Globo informações sobre os bastidores da criação e entrevistas sobre as obras, encontramos o que foi classificado pelos diretores Aguinaldo Silva e Ricardo Linhares como as primeiras obras após a ditadura militar com a característica narrativa do realismo mágico ou fantástico: Tieta (1989), Pedra sobre Pedra (1992) e A Indomada (1997) (Memória Globo, 2018). Coincidência ou não, as três ambientadas na região Nordeste. São obras importantes não só pelo estilo narrativo fantasioso e pitoresco de retratar os nordestinos, mas também pelas técnicas usadas para a abertura e o sucesso com o público. Sendo assim, as determinamos como nosso corpus analítico.

Para a seleção de leituras, entre os meses de setembro e dezembro de 2018, foram pesquisadas as bases de dados do Proquest (202 artigos), do Repositório UFPE (127 artigos), do Google Acadêmico (3.068), bem como indicações de leituras por profissionais da área. Foram adotados como descritores os termos title sequence, visual rhetoric, opening title, motion graphics, motion graphic design, aberturas, vinhetas de abertura, opening credits, telenovelas, novelas, TV Globo e Nordeste. Dos artigos e textos indicados, foram selecionadas 22 , tendo como critério de inclusão todos os que trouxessem o contexto da abertura, da retórica visual e da identidade em telenovelas. A partir disso, validamos nosso interesse na tríade de telenovelas escolhidas.

Na segunda fase, a analítica, houve uma busca por métodos de criação das aberturas escolhidas ao mesmo tempo que as telenovelas às quais pertenciam foram assistidas. Para essa busca, entrevistas, pesquisas em livros e em matérias de TV's e jornais foram avaliadas. Gostaríamos de deixar claro que as duas etapas não aconteceram de maneira linear. Apontamos essa característica para compreender como os caminhos distintos foram trilhados.

\section{Analisando milhares de imagens: a Análise Cultural de Conteúdo}

Uma abertura de telenovela dura, em média, 60 segundos. Em Tieta, por exemplo, os quadros exportados totalizam 1.873 imagens ou frames. Uma análise pode ser feita apenas em um quadro. Talvez o que contenha a logomarca da obra ou um que represente alguma particularidade de interesse do pesquisador, mas no nosso caso, vamos mapear essas 
representações pela técnica e a luminância do histograma gerado pelo agrupamento de todos os frames, como um caminho possível para encontrar a "assinatura visual" da narrativa.

A Análise Cultural de Conteúdo usa métodos de ciência de dados para auxiliar na avaliação de um conjunto muito grande de imagens. Essas ferramentas e técnicas de visualização computacional e de dados são disponibilizadas no link http://lab.culturalanalytics.info/ desde 2008. A equipe liderada por Lev Manovich desenvolveu o eixo de pesquisa Software for Digital Humanities, no qual há orientações de como usar os recursos e projetos de pesquisas compartilhadas. Um dos softwares, o ImageJ, permite criar visualizações em alta resolução dentro de vários parâmetros, como a média de escala de cinza, o desvio padrão da escala de cinza, saturação de cores etc. Já o plugin Image Montage associado ao ImageJ permite ordenar imagens pelo tempo, formato e outras classificações. Na nossa pesquisa, este plugin e software ajudaram a organizar os frames pela sequência de aparição para medirmos a média de iluminação do histograma RGB.

O histograma R (red) G (green) B (blue), perfil de saída de cores das nossas amostras que obtivemos pelo ImageJ, serve para identificar um comportamento geral de todos os frames em relação à distribuição dos valores de cinza. $O$ eixo $X$ representa os possíveis valores de cinza $e$ o eixo $\mathrm{Y}$ mostra o número de pixels encontrados, não mostrando as cores de uma imagem e, sim, a iluminação. O tom 0 é a sombra pura e representa o preto absoluto, enquanto o tom 255 é a luz mais forte e representa o branco absoluto.

Se um histograma apresenta o pico mais para a esquerda, significa que há muitas áreas de sombra na imagem, indicado que a iluminação provavelmente é artificial; mais para a direita, que há muitos brancos. Não há texturas nas regiões de preto absoluto e branco absoluto. Se o gráfico está muito à esquerda, pode-se dizer que as cores foram "cortadas", se à direita, "estouradas". Historicamente, o Nordeste é representado como ambiente de luzes com sombras demarcadas, fortes, exageradas. Para que materializemos essas impressões, para além do grid com a distribuição dos frames do Image Montage, vamos recorrer aos gráficos gerados pelo histograma RGB.

\section{Discussão}

Nesta seção, faremos um breve resumo das três obras comparando o resultado do histograma gerado e as personagens centrais.

\section{Breve contextualização das obras}

O retorno das notícias sobre Tieta (1989), Figura 4, em 2020, trinta anos depois da primeira exibição, ocorre devido a reexibição da produção na TV paga e na plataforma Globoplay. A volta da trama durante a pandemia da Covid-19 é não só uma homenagem às três décadas da obra, como também uma tentativa de amenizar os tempos difíceis. "Neste momento tão difícil que estamos vivendo, a notícia da volta de Tieta é uma alegria, um alento. A personagem 
chega para fazer o bem e rompe com tudo quanto é tipo de preconceito", comenta Betty Faria, atriz protagonista da telenovela. (Padiglione, 2020).

Figura 4: Nove frames escolhidos dos 1.872 gerados. Fonte: Memória Globo
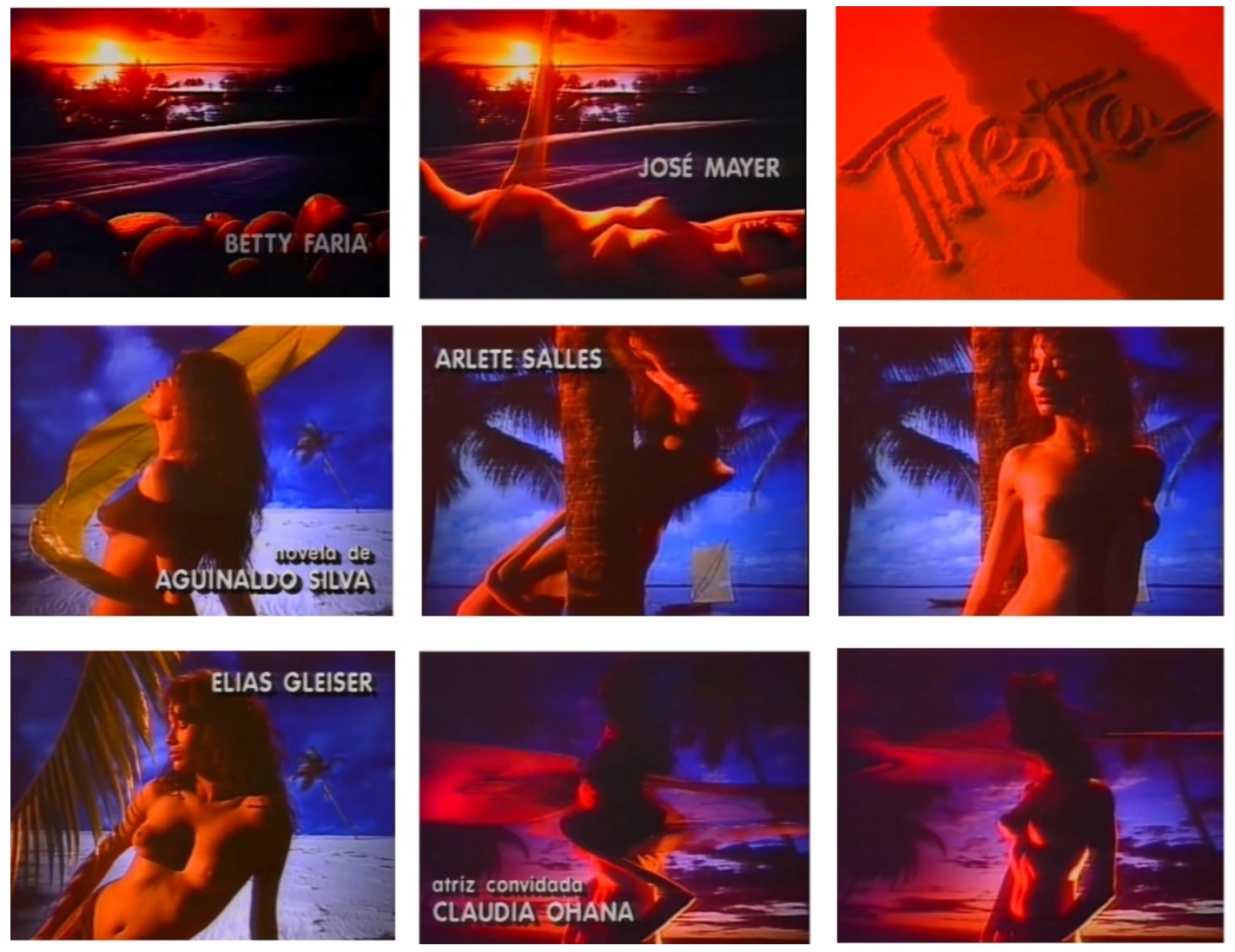

Os preconceitos citados, rompidos internamente na trama da telenovela, por assim dizer, permanecem e reforçam o contexto geral de representação visual/comportamental sobre o Nordeste. Tieta inaugura os corpos femininos nus ou seminus nas produções dos anos seguintes da emissora que também tinham aberturas representando a região. De todas as possibilidades de análises, a adaptação da obra de Jorge Amado sempre esteve presente na nossa lista. Por vários motivos, entre eles o fato de que foi a primeira novela a apresentar o efeito de distorção morph na abertura, não exatamente com o software que logo depois foi criado para isso, mas por outra técnica. Na computação gráfica, o morph cria a impressão de transformação orgânica e gradativa de uma figura em outra.

Do universo original de Amado, muito pouco foi usado. Além do nome da personagem e da irmã Perpétua, nem mesmo as características da imagem da Tieta pastora, com trajes típicos, como a que ilustra a primeira edição do livro (Figura 5), foram mantidas. 
Figura 5: Primeira edição de Tieta do Agreste (1977) com ilustração de Calazans Neto. Fonte: Fundação Casa de Jorge Amado

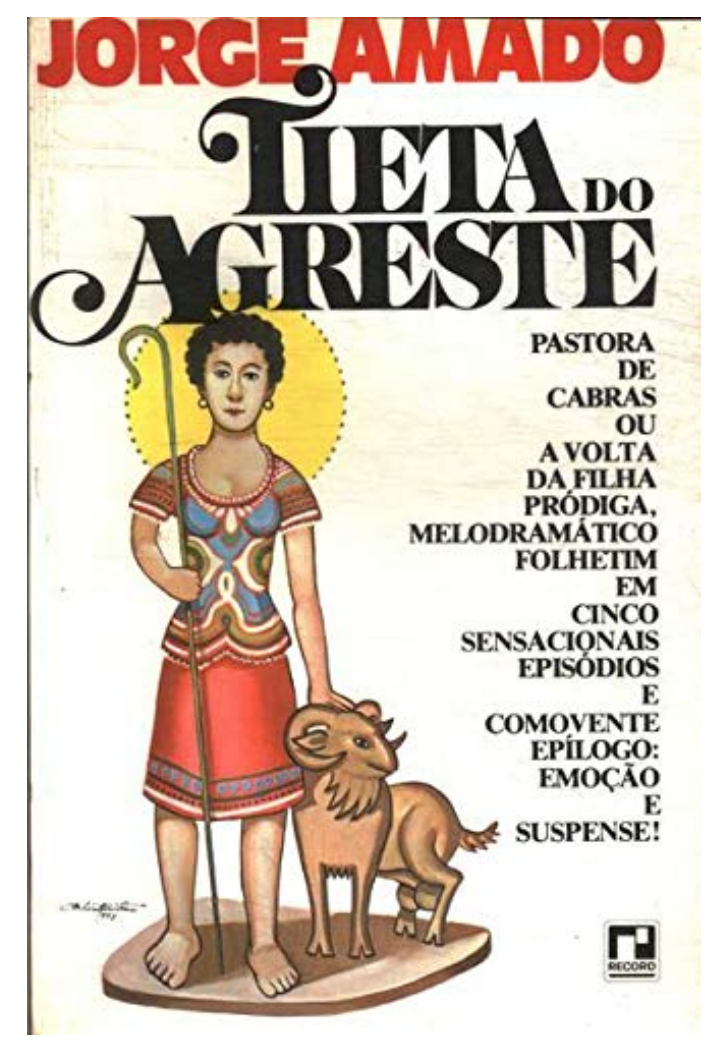

Pedra sobre Pedra (Figura 6) foi exibida pelo menos por três vezes no Brasil: 1992, 1995 e 2015, sendo que a veiculação mais recente exibição ocorreu pelo canal Viva. Trata-se da sexta novela com maior audiência no Brasil, sendo Tieta a segunda e $A$ Indomada, nossa próxima análise, a décima quarta, em uma lista das 15 produções do gênero mais vistas segundo $o$ Ibope. (BUENO, 2013). 
Figura 6: Nove frames escolhidos dos 1.608 gerados. Fonte: Memória Globo
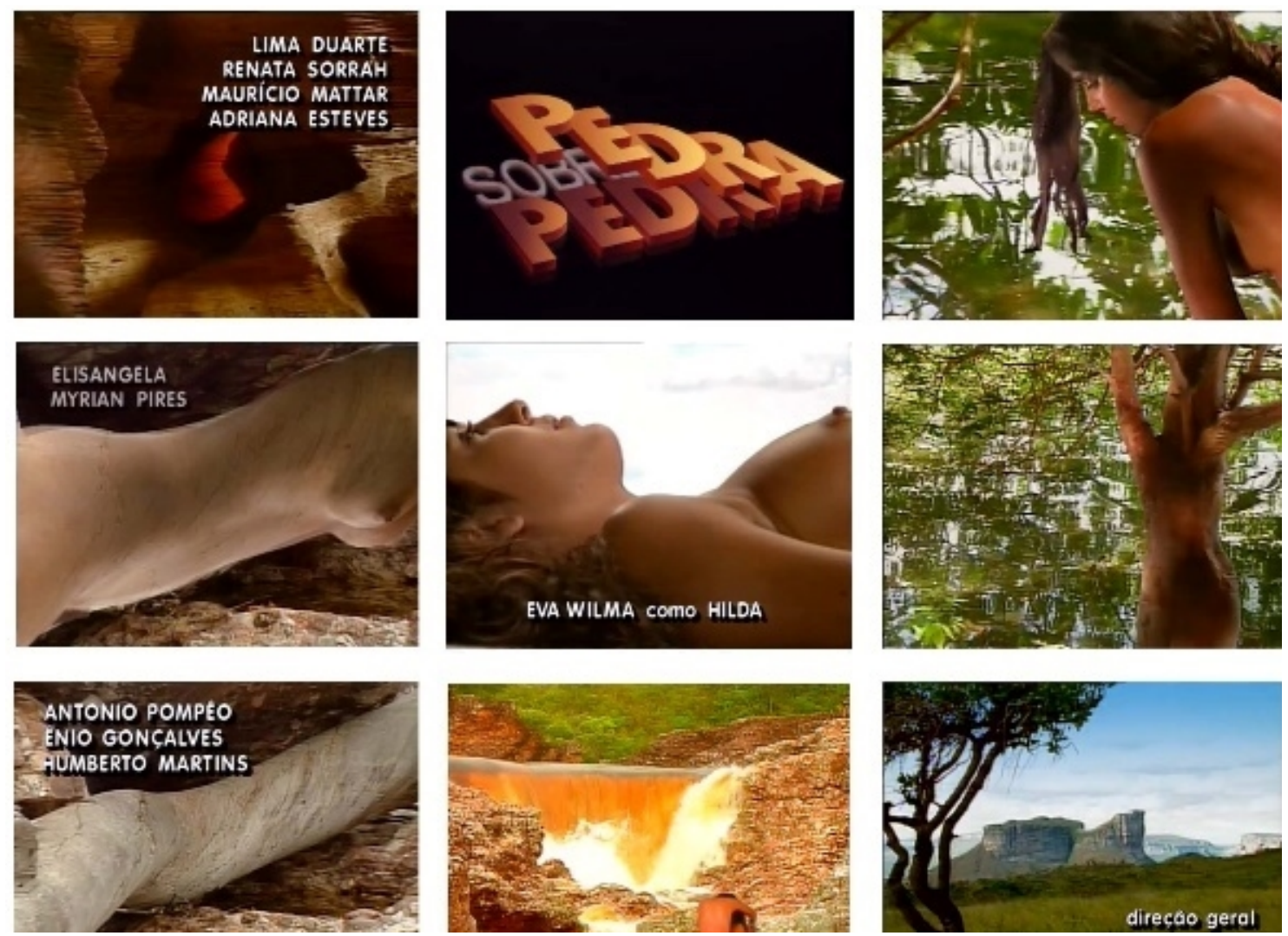

Dessa vez, apresenta-se uma região que tem, dentre outras estranhezas, uma flor afrodisíaca que encarna a alma do fotógrafo Jorge Tadeu (Fábio Jr.), assassinado após seduzir dezenas de mulheres na cidade de Resplendor. Depois de sua morte, as mulheres começam a comer essa flor que brota do seu túmulo. O realismo fantástico está presente não só na história da flor, mas na trama de Sérgio Cabeleira (Osmar Prado) que se sente atraído pela lua e em Dona Quirina (Míriam Pires), uma idosa de 120 anos que acompanha e relembra todos os fatos da cidade.

A Indomada (Figura 7) lançada em 1997, foi reprisada no Brasil em canal aberto no ano de 1999, no quadro Vale a pena ver de novo; em 2012, no quadro Novelão do Vídeo Show e, em 2018, no canal Viva, pela TV paga. Foi vendida para o Canadá, Chile, Colômbia, Nicarágua, Portugal e Venezuela, entre outros países. Em 2020, ganhou catálogo especial de exibição de grandes clássicos no Globoplay.

A trilha, a narrativa visual e mesmo as cores não agradaram aos autores Aguinaldo Silva e Ricardo Linhares. Em entrevista ao jornal O Globo, Linhares diz: "Levei um susto. A abertura é fria, a telenovela é quente. O romance ou a comédia teriam sido os melhores caminhos" (Castro, 2018). 
Figura 7: Nove frames escolhidos dos 1.618 gerados. Fonte: Memória Globo
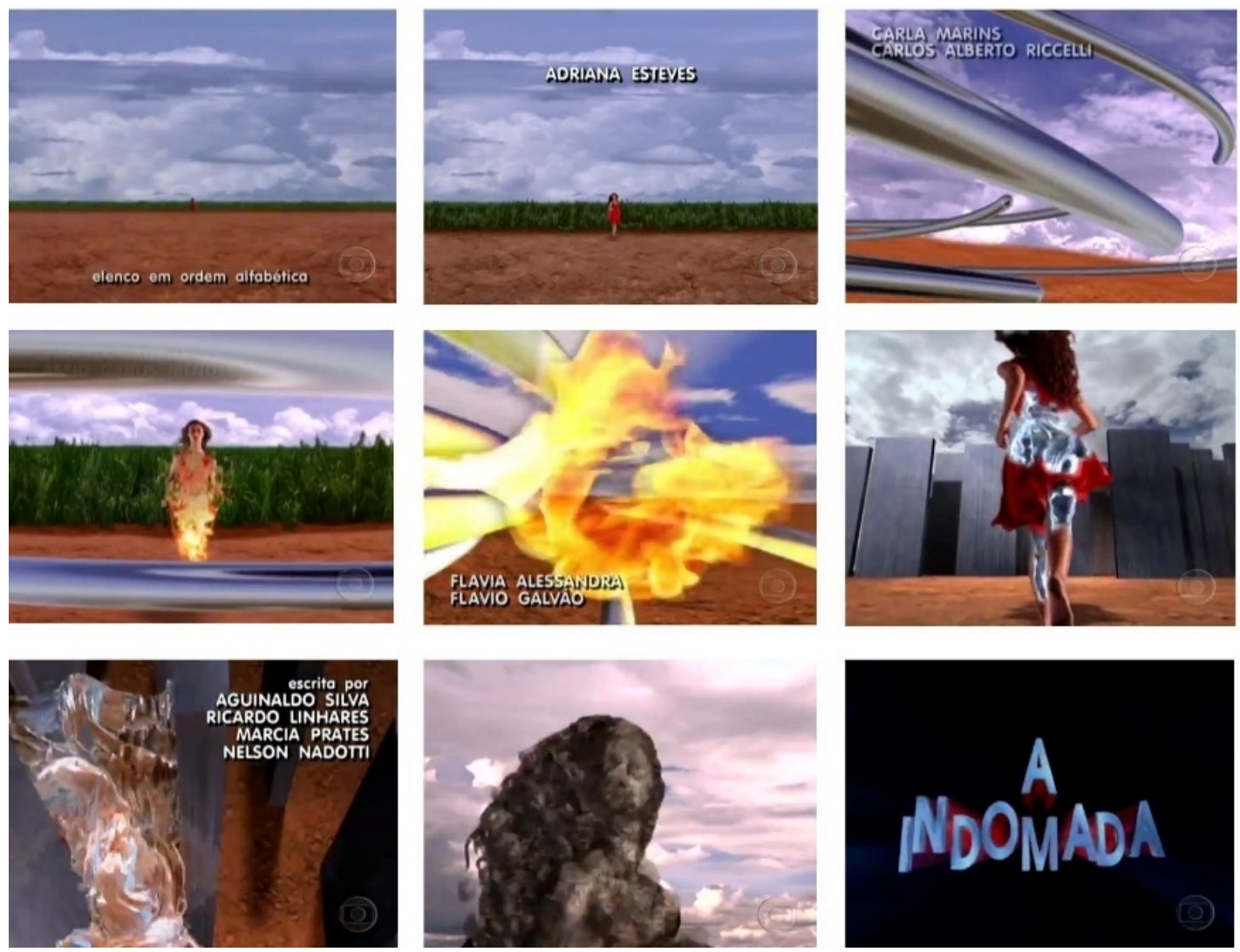

A abertura de $A$ Indomada demarca o início de um desgaste de concepção e técnicas. Desde Tieta, a fórmula da mulher que se transforma em elementos diversos foi usada com frequência, uma solução visual que acompanhava os efeitos que estavam em alta nas produções de Hollywood, o morph.

\section{Comparando os resultados}

Para que entendamos o conjunto de frames de cada trabalho, precisamos ler os resultados com seus respectivos histogramas - gerais e dos canais individuais Red, Green e Blue, Figura 8. As três produções, executadas em estúdio, tentam simular as cores e sombras de um ambiente externo. $O$ fato dessa simulação ter a intenção de representar o sol forte da região gera essa falsa iluminação de sombras demarcadas, completamente pretas à esquerda, inexistentes no mundo real. Podemos ver essa irrealidade na acentuação à esquerda do eixo $X$ em Tieta e Pedra sobre Pedra, Figura 9. Nas mesmas novelas, o eixo $\mathrm{Y}$ dos canais $R e d \mathrm{e}$ Green mostra-se acentuado, isso se dá por conta do tom avermelhado, proveniente da adição do Red e do Green, que, juntos, criam resultados em tons de amarelo. 
Figura 8: Agrupamento de Frames das aberturas e seus respectivos histogramas. Fonte: a autora

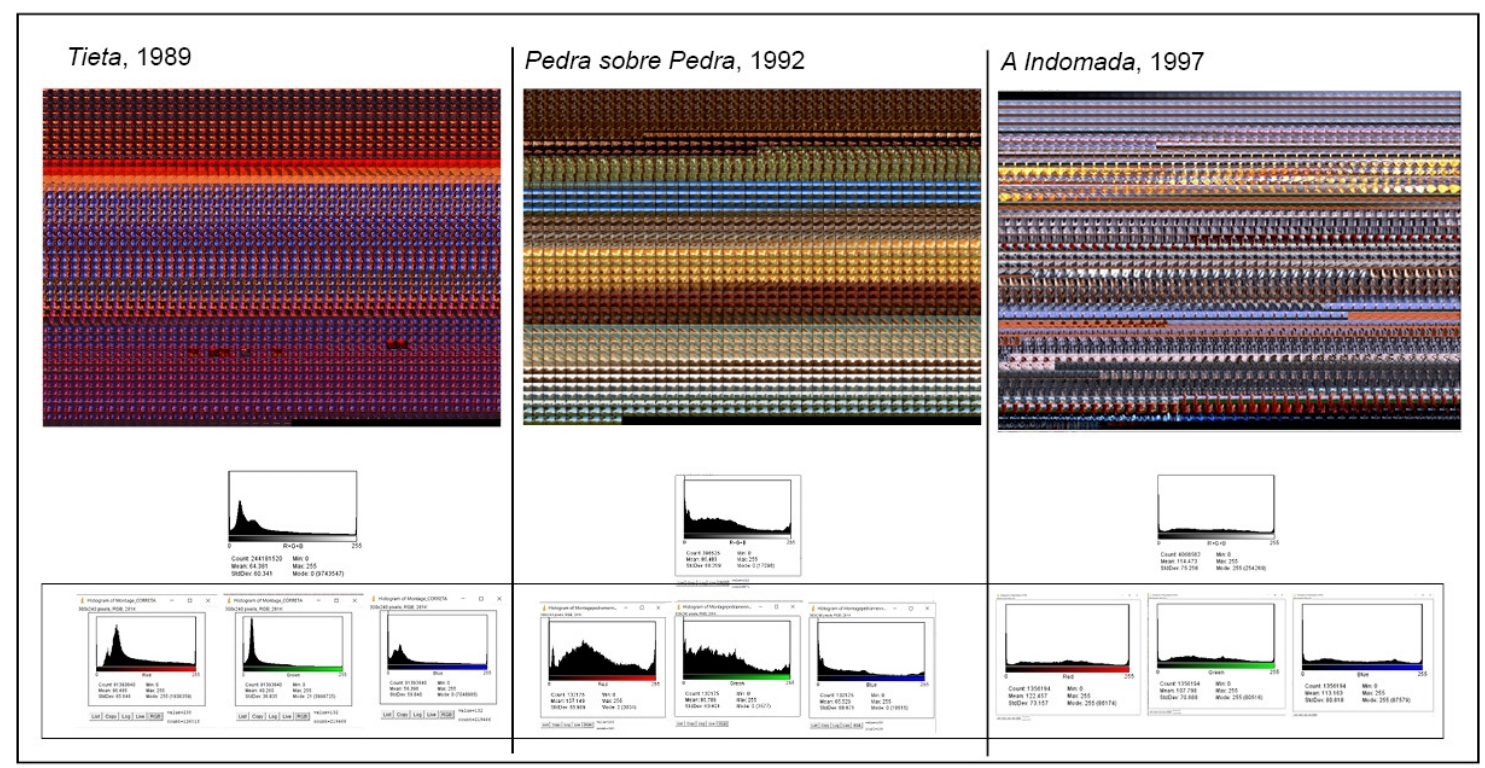

Figura 9: Histograma RGB (geral) de Tieta e Pedra sobre Pedra. Fonte: a autora

Tieta, 1989

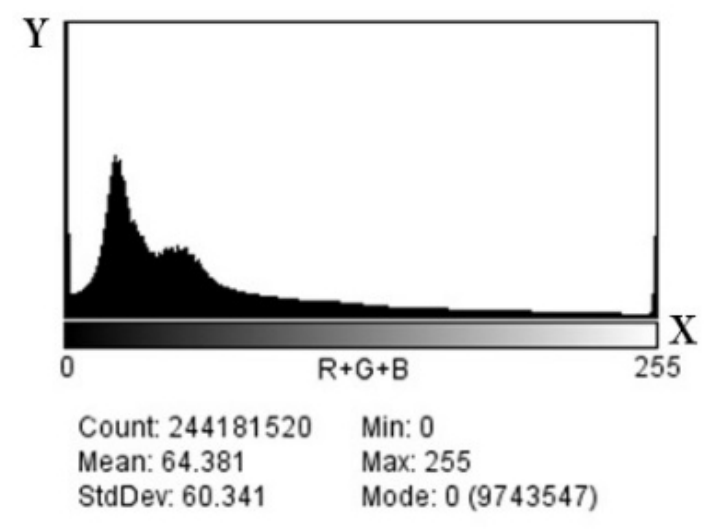

Pedra sobre Pedra, 1992

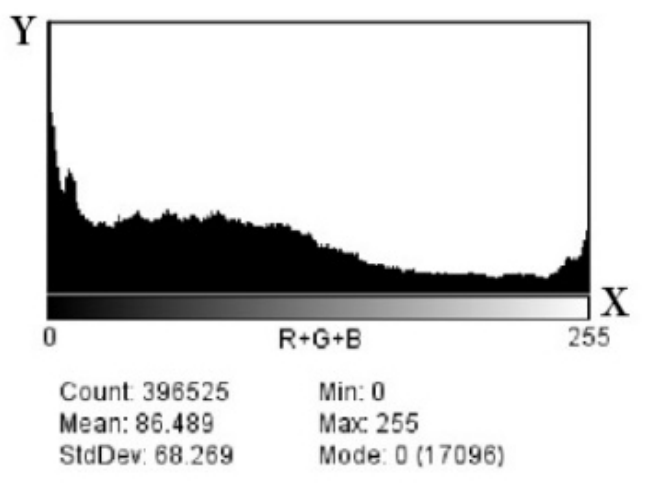

Essa tentativa, que percorre o imaginário terral - como em Pedra sobre Pedra - ou um litoral de sol forte alaranjado - como em Tieta -, é diferente na produção de $A$ Indomada, que, de maneira pontual no período analisado, apresenta tons mais frios (Figura 10). 
Figura 10: Agrupamento de frames da abertura de A Indomada e seu histograma. Fonte: a autora.

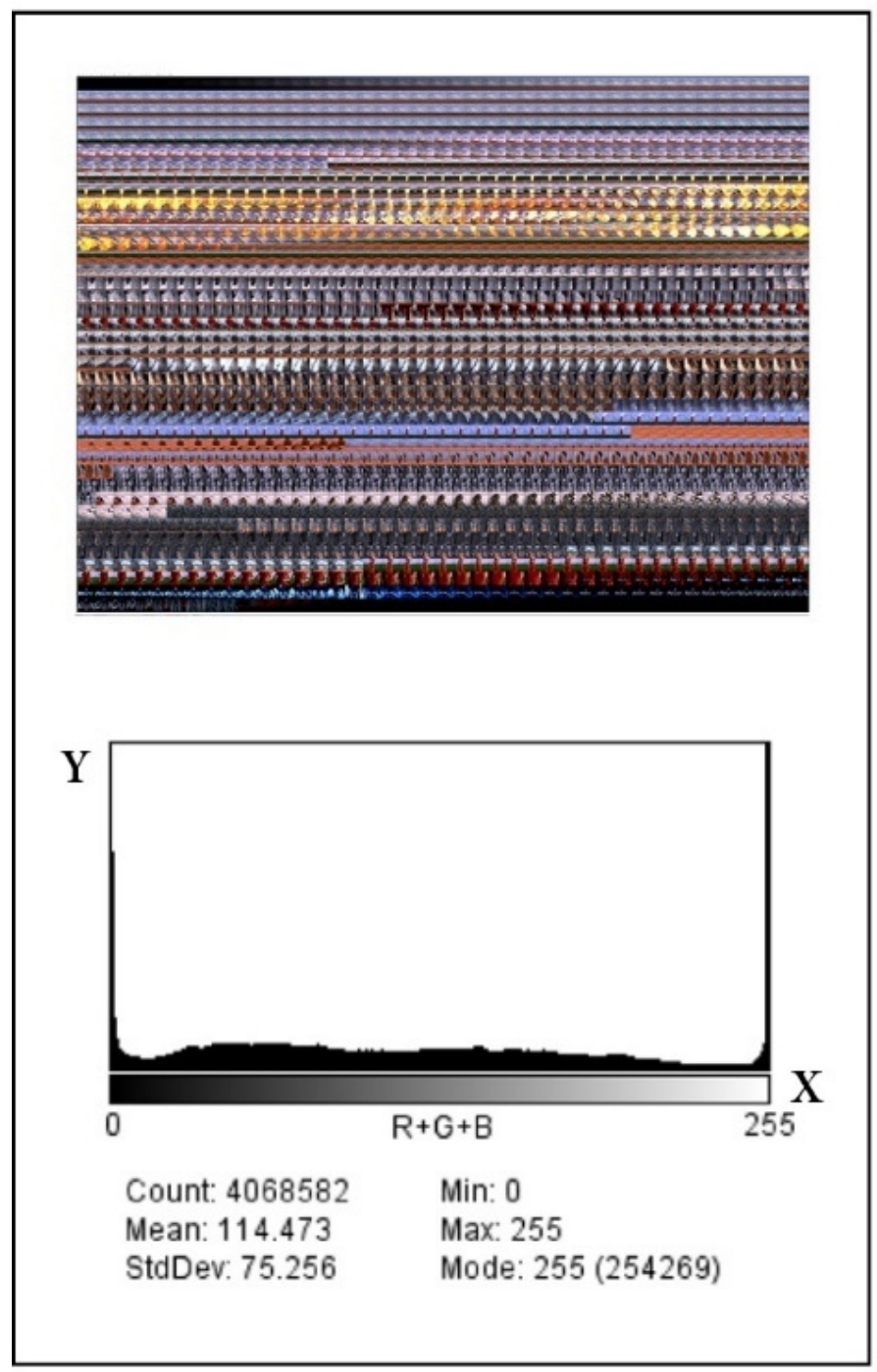

\section{As personagens}

A questão do ineditismo da abertura de Tieta não se deu apenas pela técnica, mas também pela exibição diária de uma mulher completamente nua na introdução da telenovela.

A mesma nudez é repetida em Pedra sobre Pedra. O motion graphic design, vindo do cinema, incorporou alguns modos. Nessas aberturas (Figura 11), a nudez feminina vem de um enquadramento histórico dado ao gênero. O ensaio de 1975 Prazer visual e cinema narrativo, de Laura Mulvey, fala do corpo feminino como uma extensão da câmera, conduzida pelo olhar masculino, que domina a narrativa. O mesmo se dá na publicidade, em que corpos femininos são usados para atrair o olhar e incentivar o poder de compra.(Lupton, 2020, p.120). Ser alvo do olhar, em Tieta e Pedra sobre Pedra, transforma a personagem em um ponto passivo, já em $A$ Indomada, essa passividade se transforma em alguma ação quando barreiras se rompem, mesmo que para ultrapassar as dificuldades do caminho a personagem precise de uma anamorfose, do sobrenatural. 
Figura 11: Da esquerda para direita, personagens de Tieta, Pedra sobre Pedra e A Indomada. Fonte: Memória Globo
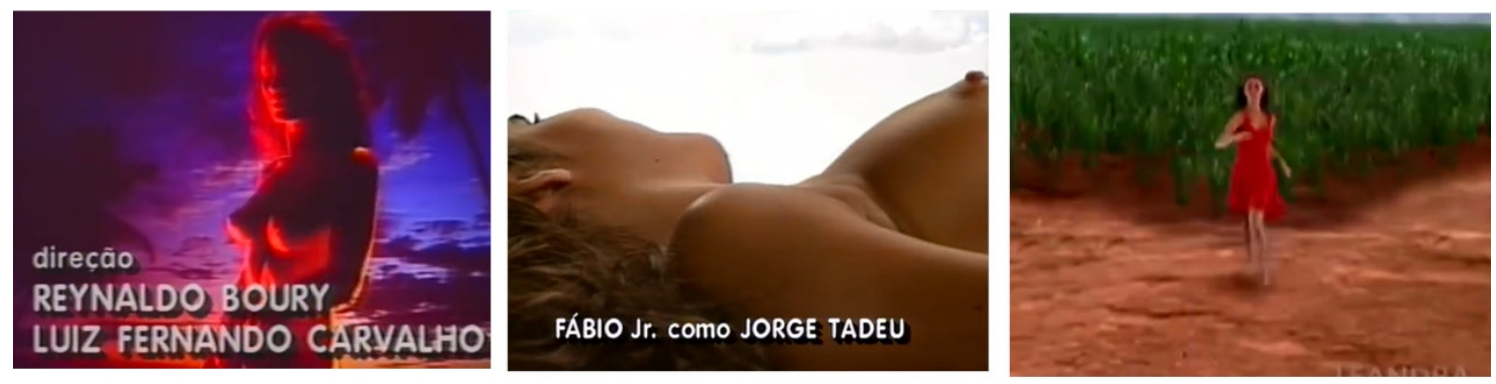

Essa decisão do uso do corpo feminino nas soluções de design, acentuada pelo olhar estrangeiro de Donner, é vista nas mulheres nuas ou seminuas em quatro aberturas de telenovelas das sete que representaram o Nordeste nos 10 anos analisados: Tieta (1989), Pedra sobre Pedra (1992), Tropicaliente (1994) e A Indomada (1997). Há aí o exemplo sobre como o design cria narrativas visuais permanentes a respeito das ideias sobre quem são os indivíduos e como se comportam. Um conjunto de simulacros mostra como a questão de identidade não depende tanto do que, de fato, é verdade, mas do que é construído para identificar determinados grupos.

\section{Considerações finais}

A TV, lançada há 70 anos, demorou pelo menos duas décadas para ser consumida massivamente no Brasil. É precisamente naquele momento de um maior número de aparelhos conectados à programação da emissora que direcionamos o olhar da nossa pesquisa. Com a Globo liderando a audiência a partir do fim da ditadura militar, destacamos métodos e ideias usados para representar o Nordeste nas aberturas de telenovelas criadas por Hans Donner e, mesmo que não creditados, por tantos outros colegas da computação gráfica e do motion graphic design. O fim da censura permitiu ousadia técnica e importação de sistemas que viabilizaram experimentalismos importantes na história do design na TV. O Nordeste, dos recursos visuais tão explorados, ganha uma nova classificação visual, a anamorfose: iniciada em Tieta, quando ocorre a transição da figura feminina em elementos naturais. Nas obras avaliadas, temos o início de uma região representada pela mulher nua ou seminua, com a capacidade sobrenatural de integrar-se à natureza.

O Nordeste como adjetivo visual ou um fetiche não é fato recente. Criado por um discurso histórico de interesses, essa representação parece destinada a permanecer enquadrada em um conjunto de ideias e soluções visuais. Se usarmos os parâmetros que definimos como análise em telenovelas recentes que se passaram na região, vamos achar histogramas com características semelhantes às produções dos anos 1990. Por exemplo, o histograma da supersérie Onde nascem os fortes (2018), resultou em características similares aos de Tieta e Pedra sobre Pedra. Se observarmos a partir das técnicas de VFX, também não será difícil encontrar os princípios anamórficos - o que começou com uma mulher, hoje pode ser uma 
criatura que se transforma em elementos da natureza, como na telenovela Velho Chico (2016). Expresso em outros termos, nosso corpus analítico é uma matriz do que exaustivamente vem sendo repetido nos anos seguintes.

\section{Referências}

Albuquerque Júnior, Durval Muniz de.(2011). A invenção do nordeste e outras artes. 5 ed. São Paulo: Cortez Editora.

Artes e Artistas. (n.d). Biografia de Carybé e sua obra. [Web page] Disponível em https://arteeartistas.com.br/biografia-de-carybe-e-sua-obra/

Beccari, Marcos Namba. (2015) Articulações simbólicas: uma filosofia do design sobre o prisma da hermenêutica trágica. [Tese de doutorado]. Departamento de Educação, Universidade de São Paulo, São Paulo.

Castro, Daniel. (2018, Setembro 23). Em 1997, abertura de A Indomada causou guerra entre Aguinaldo Silva e Hans Donner. [Web page]. Disponível em:

https://noticiasdatv.uol.com.br/noticia/televisao/em-1997-abertura-de-indomada-causouguerra-entre-aguinaldo-silva-e-hans-donner--22474?cpid=txt

Carpeggiani, Schneider. (2007) "Tu me acostumbrastes": Como Alberto Fuguet repensou o legado do Boom de Gabriel García Marquez. [Dissertação de mestrado].Departamento de Letras, Universidade Federal de Pernambuco, Recife.

Cintra, Jaíne. (2020). O Nordeste em segundos: as aberturas de telenovelas da TV Globo (1989-1999) [Dissertação de mestrado não publicada]. Departamento de Design. Universidade Federal de Pernambuco, Recife.

Dorneles, Rogério de Abreu. (2007) O design na teledramaturgia: um olhar sobre as vinhetas de aberturas das telenovelas da TV Globo. Departamento de Design. Pontifícia Universidade Católica do Rio de Janeiro, Rio de janeiro.

Flusser, Vilém. (2017). O mundo codificado: por uma filosofia do design e da comunicação, org Rafael cardoso. São Paulo: Ubu Editora.

Fonseca, Fabio. (2011). O bestiário medieval na gravura de Gilvan Samico. [Dissertação de mestrado].Departamento de Artes, UNB, Brasília.

Memória Globo. (n.d). Hans Donner. [Web page]. Disponível em: https://memoriaglobo.globo.com/perfil/hans-donner/

Fortv. (2014, Setembro 09). Hans Donner, o designer da Globo. [YouTube]. Disponível em: https://www.youtube.com/watch?v=4cbrgF3puqA

Lupton, Ellen. (2020). O design como storytelling. São Paulo: GG editora.

Jucá, Betariz; Oliveira, Joana.(2020,Outubro 18 ). Movimento Armorial, 50 anos do convite para que o Brasil mire as suas entranhas. [Web page]. Disponível em: https://brasil.elpais.com/brasil/2020-10-18/movimento-armorial-50-anos-do-convite-a-que-obrasil-mire-suas-entranhas.html

Maciel, Neila Dourado Gonçalves. (2015) Carybé e a legitimação de um discurso da baianidade na integração das artes em Salvador. [Tese de doutorado]. Departamento de Arquitetura, UFBA, Salvador. 
Manovich, Lev. (2012, Março 30) Guide to visualizing video and image sequences. [Web page]. Disponível em http://www.softwarestudies.com.

Memória Globo.(n.d) A Indomada. [Web page]. Disponível em:

http://memoriaglobo.globo.com/programas/entretenimento/novelas/a-indomada.htm

Memória Globo.(n.d).Pedra sobre Pedra. [Web page]. Disponível em:

http://memoriaglobo.globo.com/programas/entretenimento/novelas/pedra-sobre-pedra.htm

Morais, Silvano. (2020, Fevereiro 22). Abertura da novela Tieta: Bastidores do making off. [YouTube]. Disponível em https://www.youtube.com/watch?v=nvaOx5JAupM.

Pater, Ruben. (2020). Políticas do design. Um guia (não tão global) de comunicação visual. Tradução de Antônio Xerxenesky. São Paulo: UBU Editora.

\section{Sobre o(a/s) autor(a/es)}

Jaíne Cintra, M. ${ }^{a}$, UFPE, Brasil, <jainecintra@gmail.com>

Paulo Carneiro da Cunha Filho, Dr., UFPE, Brasil, <pauloccunha@gmail.com> 